\title{
Partnerships between universities and workplaces: Some challenges for work integrated learning
}

\author{
Sarojni Choy and Brian Delahaye \\ Faculty of Education, Queensland University of Technology \\ Brisbane, Australia
}

Email: s.choy@qut.edu.au

\begin{abstract}
Under contemporary highly competitive markets, organizations are demanding that any investment in learning be converted into productive outcomes that rapidly progress the organisation towards pre-defined strategic goals. A customised work integrated learning curriculum has the potential to achieve such productive outcomes because it allows learners to quickly contextualize the study content within the socio-cultural and functional environment of the workplace. However, the development of a work integrated learning curriculum relies on genuine partnerships between the universities and organisations. These types of partnerships require lengthy processes of negotiating the curriculum and pedagogies to support learning based in the workplace. Predictably such partnerships challenge the traditional roles of the universities as transmitters of discipline specific knowledge, and the workplace as less active partners in the learning processes and products.
\end{abstract}

This paper is based on a case study and relates the challenges of developing a partnership, the transformed role of the academics, and a more complex design and facilitation of the curriculum. What became evident was that such a partnership was problematic and demanded re-distribution of knowledge- power relations between the university and the host organisation. The findings substantiate that successful work integrated learning that meet the needs of individuals and their workplaces is premised on a learning partnership where the roles for the curriculum and pedagogy are genuinely shared. That such partnerships are integral to successful work integrated learning and deeply problematic, begs for more research to understand the dynamics and ways to approach learning partnerships between universities and organisations.

Keywords: Work integrated learning; workforce capacity building; partnership, powerknowledge relations.

\section{Introduction}

Organisations investing in university courses to develop workforce capacity, predictably expect a quick return in the form of productive outcomes that rapidly progress identified strategic goals. Driven by this expectation, universities have adopted work integrated learning (WIL) as an essential component of experiential learning for students. Work integrated learning - where the academic curriculum is aligned with work tasks - offers learning experiences for worker-learners to focus on outcomes that serve such expectations. Both learners and their employers prefer the 
learning challenges to be based on the exigencies of work to precisely reflect real work circumstances that overtly add to business outcomes. Learners engaged in WIL are not only required to demonstrate an understanding of new knowledge but must also apply that knowledge in ways that perceptibly benefit the organisation. This illustrates a dual emphasis on the development of both the learner and the organization through WIL.

However, alignment of academic content to workplace activities is often complicated and challenging for academics, principally because there are no preexisting maps that chart the territories of knowledge in academia and industry (Boud and Symes 2000). To compound this situation, universities traditionally hold a vendor relationship with clients needing educational services. Wright (2008) warns that a vendor relationship has underlying expectations that, for the money invested by organisations, the provider will find solutions to problems. As such, the purchaser sees little need to invest too much time or effort in shaping the curriculum or processes for learning, but place great importance to the product or outcomes of learning.

To overcome these deficiencies and to fulfil the promise of WIL, there must be appropriate interactions between the presage, process and product which form the 3 Ps in Biggs' (2007) model of curriculum. Inevitably, innovative models of work integrated and work-based learning require universities to work in partnership with workplaces to appropriately design and facilitate learning in the workplace. This is because members of both organisations (universities and the workplace) own domain knowledge and expertise that contribute significantly to productive WIL. That is, each holds distinct sets of expertise to be drawn together in order to shape the curriculum. For instance, those from the workplace can have more input about the intricacies of 
the presage within the workplace environment and the product factors that contribute to the types of business like changes expected from the learning experiences. Academics with expertise in pedagogies and epistemology and with help from the members of the workplace are better placed to package the theoretical content into the context of the workplace. Therefore, the partnership requires new 'power knowledge' relations, and the territories need to be negotiated and mediated. Collaborative self-interest, transparency and negotiability, according to Smith and Betts (2000), must be central in such relationships. Moreover, Watter’s (2005, 47) notion of sharing (straightforwardness; honesty; shared accountability; risk taking; integrity; negotiation; and clear and jointly owned goals) is paramount.

Therefore, the development and implementation of the curriculum, where course content is fused with work tasks, requires a partnership between the university and the organisation. This is important because while the academics may hold dominance in content and theoretical knowledge base, productive application of these for transformations in the distinct context of the workplace is premised on the sociocultural environment and relies heavily on the tacit knowledge of the workers. Hence staff from both institutions need to work in partnership to facilitate the interactions between Biggs’s (2007)3 Ps.

A partnership for WIL implies that academics are no longer the dominant players. Solomon and McIntyre (2000) advocate that academics need to break away from knowledge codes' that long existed in the university domains because work based learning represents ‘deschooling’ of vocational knowledge therefore partnerships for WIL do threaten existing power-knowledge relations. Their views support Torraco's (1999) claim that the evolution of work and of expertise needed to perform it, have not been accompanied by innovations in the models used by 
educators to develop this expertise. These views beg more discussions on the nature and processes for partnership that deliver successful WIL.

This paper reports an instrumental case study (Stake, 1995) that demonstrates the authors' approaches to the development of a partnership with a non-government organisation (NGO). On this case, the partnership was developed for co-constructing the curriculum and designing the teaching and learning approaches for workerlearners - unlike other partnerships that focus on logistics for experiential learning opportunities for students. The authors relate the challenges they experienced in building a sustainable relationship, the transformed role of the academics, and mediating a more complex design and facilitation of the curriculum. The workplace other than their university was a 'foreign' territory for academics therefore the design of learning experiences in the NGO demanded substantial input from worker-learners and their managers. Their involvement was critical to the development of a program with real stakeholder ownership, one that clearly defined the outcomes for the organisation as well as individual worker-learners.

The processes in forging the partnership highlighted the importance of extensive engagement with worker-learners, their supervisors, the academic team and the university administrators. This necessitated a sharing of 'power' or authority on aspects of the learning experiences that constitute the academic curriculum. The authors found that a partnership for a WIL curriculum is deeply problematic and go on to propose for more research to understand the dynamics and ways to engage a range of personnel from across the university and the organisation engaged in WIL.

\section{The challenge to universities}

As the accrediting bodies, universities generally display more authority or power over the content, types of learning activities and outcomes that manifestly meet the 
academic standards. While this arrangement serves well the interests of the university, it falls short of adequately meeting the needs of the workplace and learners. Yet, a collaborative design of WIL would potentially better serve the needs of all three parties. However, the break away from the "almost ideological attachment to the pedagogical [or traditional] model” (Knowles 1980, 59) presents a challenge to many universities. A positive alignment between learning and observable business outcomes requires a partnership with genuine re-distribution of power between the learners, academics, workplaces and university administrators to move beyond a teaching orientation to a demonstrably effective learning environment. To create conceptual change as a purpose of learning (Biggs 2007), WIL is embodied in the context of work, organized and intentional in order to trigger transformations in individuals as well as their workplaces. The design of WIL necessitates input from all stakeholders because learning in the workplace is socially distributed, co-produced and legitimized by worker-learners and the academics. In a recent study Harris, Simons and Moore (2005) researched the effectiveness of partnerships between selected VET providers and industry and found that distribution of knowledge, resources and power is inevitable. They concluded that each has much to benefit when all parties are committed and take responsibility. For universities, then, the challenge is to move to a more proactive and complex approach to the management of learning so that the knowledge is indeed integrated into the workplace. Because successful WIL necessitates a partnership between the university and the management in the workplace as well as its worker-learners, the development and maintenance of such a partnership takes time and effort, and can be challenging for academics. The case study below relates some challenges experienced by the authors. 


\section{The case study}

This paper draws on evaluation data and reflections of the authors on a case study that negotiated the curriculum with a cohort of learners, their managers, other academics, and the university administrators. The aim of the partnership between the university and the NGO was to design and facilitate a customised curriculum to develop the leadership capacities of twelve worker-learners through a postgraduate course. The project began with the development of an organisation-centred curriculum framework (see Choy and Delahaye 2008). Inevitably, this was a collaborative exercise that drew on the expertise, experiences and knowledge bases of a team from both institutions, each having existing relations of power. For instance, while the academics were conversant in leadership theories and potential applications in the workplace, the staff at the NGO had a better sense of what would or would not work in terms of its diverse functions. They had the tacit knowledge and understood the sensitivities within NGO's broader work context at the industry level. The exercise of mediating the two sets of knowledge bases (of academics and staff in the NGO) demanded constant renegotiation to form a functional partnership that respected each other’s territories and collaborated to meet dual needs (of the university and the NGO). This instrumental case study (Stake 1995) illuminates some issues in developing and implementing a partnership for a WIL curriculum.

To address the complexities and challenges, the authors used a number of guidelines, suggested by the literature, to customise existing academic units. These guidelines have been the topic of previous publications (Choy and Delahaye 2009a, 2009b; Choy and Delahaye 2008; Delahaye and Choy 2008, 2007). Briefly, the guidelines included: the academic units were selected and then customised based on the strategic needs of the organisation (Sims 2006); the learning and assessment used 
andragogical principles (where the learners take responsibility for their learning) to encourage the worker-learners to accept responsibility of converting the theoretical concepts into work-based change (Knowles, Holton and Swanson 2005); maximised the use of both formal learning (online and face-to-face workshops) and informal learning (through peer interaction, one-on-one discussions with the academics and presentations to work colleagues) (Enos et al. 2003; Jackson et al. 2003); used learning cohorts with each focusing on specific strategic change interventions; and ensured that the assessment was clearly and strongly linked to the strategic change required by the NGO. Four units - Leadership for Change; Politics of Diversity and Identity; Knowledge Management; and Changing Agendas in Leadership - were packaged for the Graduate Certificate in Education (Educational Leadership) course. A team of three academics delivered the course and two others contributed as experts.

An evaluation, funded by a teaching and learning grant from the university, was completed half way through the course. Data were collected from interviews with ten participants. The transcripts were analysed using the constant comparative analysis technique (Creswell 2008) where categories of data under each theme were compared. The preliminary findings of the project were then presented to a focus group of six interviewees for validation and discussion.

Two features made the partnership in this case study different from other industry-university partnerships. First, there was a transition of a traditionally educational program, designed specifically for school teacher training, into a noneducation industry sector. This transition presented challenges in the development of a partnership with participants from both institutions being only remotely familiar with each other's areas of work. The NGO that sought a WIL approach to the development of its leadership capacity was in the business of brokering training to develop the 
health and community services sector workforce in the State of Queensland, Australia.

The second feature of differentiation was a customised curriculum that was co-produced and aligned to the strategic goals of the partner. It was an orientation from a traditional 'supply' to a 'demand' driven curriculum (see Wright 2008). The content for the study units was collated in collaboration with the participants. The academics ensured the integrity of the standards and quality of the university's postgraduate award. The pedagogy for this curriculum was designed to meet the learning needs of the individuals, at the same time achieve relevant strategic goals of the NGO. The learning activities were aligned to individual's work roles, thus met the individual learning needs, and these subsequently linked with the strategic goals of the NGO. In this way, the design was embedded and embodied in the workplace to serve the leadership development needs of the individuals and the NGO. Considering that the NGO expected a return on its investment through sponsorship, an organisation centred curriculum was crucial because learning needed to translate into organisational changes. Therefore, it was the NGO that became the primary 'learner' and its learning (in the form of organisational change) was facilitated by individuals learning to make the desired changes in their work practices.

Following the completion of the project, this paper is based on the reflection by the authors both on their experiences and the evaluation results. This paper is structured under three headings - building a sustainable relationship, the changed role of the academics, and a more complex design and facilitation of the curriculum.

\section{Building a sustainable partnership}

Three changes were noted in the partnership with the NGO: 
(1) the relationship moved beyond short-term to an on-going partnership that still exists

(2) senior management was highly involved

(3) the NGO involved the university in its strategy and not merely in a technical task or isolated problem.

These changes resulted from lengthy negotiations and re-distribution of power relations between the two partners. In achieving these three changes though, two specific activities were of critical importance - establishing an open relationship and gaining partnership familiarity.

\section{Establishing an open relationship}

It took a long time - over six months - for the authors to build a trusting relationship and sufficiently understand the needs of the NGO. The process relied on open and honest communication of the positions of each party. Each institution came into the partnership with its own threshold or operational boundaries, with some elements that were negotiable and others inflexible. The figure below illustrates the two sets of thresholds that each partner felt strongly about.

Figure 1 University and industry thresholds 


\section{University \\ Industry \\ Threshold Threshold}

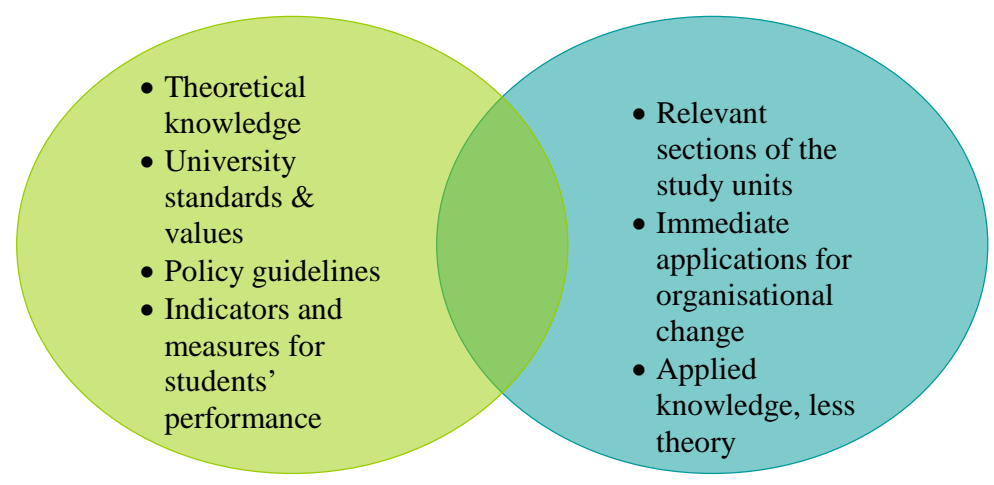

As the two partners gained better understanding of each others' needs and thresholds and willingness to re-distribute roles, the intersection of the two circles in the figure gradually expanded.

The NGO was interested in relevant sections of the study units, expecting immediate applications to respond to issues and trigger organisational change. The focus here was more on applied knowledge rather than the theories and university assessment for a postgraduate course, as explained by the Executive Director of the NGO.

...we're really keen to do some work around leadership, but fundamentally it needs to be linked into the way we operate. It's meant to be associated with the type of principles that we work on, that in fact, what we're doing in that regional capacity building or organisational capacity building across the sector. 
An open relationship facilitated learning by both institutions - the academics gradually learned about the complexities of the NGO while the worker-learners in the course understood the theories and ascertained ways to apply these in the specific context of their work.

The academics on the other hand were bound by the university standards and values, the policy guidelines, and the indicators and measures for student performance. In general, the emphasis of the university was on theoretical knowledge, with expectations that the worker-learners would apply these in their organisational context. There was an assumptions that the learners fully understood the nature of their work issues and that they had the skills and understanding to be able to integrate, and achieve the types of changes the NGO expected. What came to light were the deviations caused by the movement from intended to emergent strategic goals (Mintzberg 2003), and that many worker-learners could not derive a learning solution from the study units as a response to their work issues. This had to be facilitated through an iterative process, with the academics playing an active role, and employing appropriate pedagogies including constant questioning, critical analysis and reflective thinking. Overall, the partner familiarity exercise facilitated a deeper relationship where transformations resulting from learning became a shared responsibility and both parties were active learners.

\section{Partner familiarity}

When the thresholds of each party were acknowledged and legitimised, the interactions moved to a deeper level so that each party could gain thorough understanding of each other's organisation. This was largely facilitated by sharing (Watter 2005) with both parties negotiating by being straightforward and honest about their positions, and appreciating the risks. A liaison person from the NGO and the 
university (first author) jointly prepared draft proposals/papers for internal discussions and approval. A trusting relationship was facilitated by openly discussing the precise nature of outcomes expected by the organisation; its level of commitment to resources; the cost (in quantitative and qualitative terms where possible) to the NGO of its staff not engaging in the learning; and the constraints and parameters that both partners operate in. It involved introducing each other to the organisational culture, procedures, systems and 'languages' commonly used, understanding the constraints and parameters that each operate in, and assessing the potential risks. The point about 'languages' was critical here because academic language is rarely used in industry contexts. According to Dyer and Singh (1998) and Zahara and George (2002) understanding each other's processes, procedures and ways of operating enables knowledge sharing routines and increases the capacity to absorb knowledge from the source partner. Such understanding relies on thick communication.

As staff from the university and the NGO interacted and gained a deeper appreciation of one another's procedures and ways of doing business, their understandings in turn eased knowledge sharing routines and increased the capacity to absorb additional knowledge from each other. According to Sherwood and Covin (2008) this type of partner familiarity was predictive of both explicit and tacit knowledge acquisition. While explicit knowledge is easy to identify and made tangible, the partners are not necessarily aware of or value each other's tacit knowledge. The academics took time to explain the concepts of explicit and tacit knowledge, and assist the managers and course participants to understand the differences and access the two types of knowledge. The importance of particularly tacit knowledge for WIL was discussed at length and the worker-learners saw it as a powerful tool when discussing and negotiating aspects of change they expected as a 
result of what they were learning in the course. The power of the tacit knowledge for partnership processes can not be underestimated, as explained by Foucault (1980) that partnership processes are surrounded by power that is exercised and embedded in the complexities of relationships and discourses. Hence such power needs to be managed sensitively and trustfully. Because the NGO had gained trust of university staff who had regularly interacted and understood its business well, it wanted to have some influence over which academic takes responsibility for scaffolding and coordinating the study units so an informal arrangement was agreed until the completion of the program.

What was becoming apparent was that the relationship relied heavily on a few staff who had engaged and gained the trust of the NGO as well as of its networks and stakeholders. For the academics the sharing of their traditional 'powers' over the curriculum felt uncomfortable at the beginning. They controlled subtle resistance to devolving power especially over content, particularly in the first semester when responsibility over their normal professional practice was being contested. According to Williams (2004, 94), this is not unusual, 'Any configuration of power knowledge opens up its own particular spaces and moments for resistance'. However, the benefits they gained from thick communication and relationship building to gather and understand the context gradually dispelled any initial fears and resistance and exercised a change to the academics' roles for WIL.

\section{Changed role of the academics}

The academics experienced a transition from traditional 'teaching' roles that were different in focus, purpose and practice. It meant a transformation of identity, traditionally shaped by discipline expertise. Engagement and input from the NGO into the development and design of the program challenged their assumptions about 
managing learning in their professional areas of expertise. Quite some time ago, Knowles (1980) recognised this conundrum by suggesting that facilitators of adult learning need to release their ideological attachment to managing content and, when appropriate, embrace the assumptions of andragogy - where the learner could take control of deciding what should be learned, how it should be learned and what evidence is needed to demonstrate that the learning has occurred.

\section{Atypical roles of academics}

As the academics ventured into WIL in customized study units for the NGO, they assumed a role atypical of academics. Normally, the business manager in the faculty plays a leading role in building relationships with enterprises for formal contractual purposes. However, in this instance the academics remained at the forefront of the delivery and the university 'face'. A change in their role initiated deep reflection and review of their identities as academics.

\section{Right people}

Harris, Simons and Moore (2005) recommend that selecting the 'right' people in terms of their ability, attitude and personality is critical to the relationship building and maintaining processes. These 'right' people, need to understand how the awards and course content will serve organisational needs. They need to appreciate, understand and commit to a WIL approach to course delivery. Harris et al. (2005) also suggest that the academics need skills to 'suss out' much of the tacit knowledge to comprehend the dynamics within the work environment - a task that takes time and is not so easy for 'outsiders'. The approach by the authors of this paper insisted a degree of sensitivity that influences power relations between the academics representing the university and managers from the partner organisation. Finally, the authors found that a good knowledge of strategic planning was needed, not just fully understand the 
strategic direction of the organisation, but to help the organisation to clarify the sometimes disparate interpretations of the strategic goals and plans. These formed the underpinning knowledge that informed the complex design and facilitation of the curriculum.

\section{Complex design and facilitation of the curriculum}

The energy released by the open communication within the learning partnership had a significant transfer effect on the subsequent curriculum design and facilitation. Five specific observations came to light - the emphasis on development of tacit knowledge, the use of thick communication channels, control of the design and facilitation, releasing control over the content, and the need for flexibility.

\section{Development of tacit knowledge}

The importance of tacit knowledge in the university-enterprise learning partnership provides one of the key movers that change the traditional power of universities. The significance of tacit knowledge became apparent in two ways. Firstly, the academics who brokered the WIL arrangements between the university and the NGO needed to acquire tacit knowledge about operations in the workplace - the learning site.

Predictably this took time and constant negotiation and verification with the learners and their managers.

Secondly, the content knowledge about leadership and management to be acquired by the learners had to translate well to their tacit knowledge. This was important as explained by Sherwin and Covin (2008) that the learning partnership between universities and organisations are best used for non-codified tacit knowledge, rather than explicit knowledge. They explained that explicit knowledge is potentially codifiable in form and therefore can be more easily verified while 'tacit knowledge, 
by contrast, tends to be more ambiguous in scope, embedded in practice or skill sets, and difficult for the knowledge source to "surface" for conscious consideration and transference purposes’' (Sherwin and Covin 2008, 177). Work integrated learning is based on the assumption that the new knowledge to be developed by the organisation is tacit, rather than explicit, in nature. This implies a major shift from university's 'products' in the form of explicit codified knowledge to 'services' to assist in the development of productive tacit knowledge. Universities are often seen as vendors of 'products'. Wright (2008) argues that 'seeing a university as a vendor rarely produces significant outcomes for a corporation” (p. 76). It is the nature of services that facilitate the development of tacit knowledge which result in significant outcomes and add value to the business of the workplace. Embedding such services requires academics to develop tacit knowledge about the enterprise's business, and realising that they will be able to access only the minimum that exists at the surface. This is because the development of tacit knowledge relies on enculturation to the workplace (Lave and Wenger 1991), to facilitate the transformation and construction of knowledge that is vocationally and socially meaningful. Tacit knowledge was increasingly gained through frequent visits, engagement in activities other than the delivery of the course (eg. work projects, advisory panels, seminars, professional development workshops, and industry forums) and thick communication channels. They concentrated on services that could generate the flow of tacit knowledge between the learners, the NGO and the university, and relied heavily on thick communication channels.

\section{Thick communication channels}

The intensity of communication required for WIL in this case study was grossly underestimated at the beginning. This miscalculation reflected an assumption that the 
power balance, particularly with decisions about the content, would lean towards the university. However, the challenges of converging towards the development of tacit knowledge for WIL highlighted the significance of thick communication channels at all levels within the workplace and the university. Thick communication channels are supported by network theory which maintains that weak ties are more suited for acquiring codified explicit knowledge while strong ties are more appropriate for importing non-codified tacit knowledge (see Hansen 2002; Regans and McEvily 2003). Strong ties are signified by relationship strength (time spent developing the relationship, emotional intensity, mutual confiding and degree of reciprocity) and network density (the extent that network nodes are directly connected to each other) (Regans and Zuckerman 2001).

A combination of technology-mediated (e.g. e-mail and telephone) interactions, site visits and face-to-face dialogue were included. Furthermore, interactions with some of the NGO's networks and stakeholders also added to the tacit knowledge base of the academics. As thick communication channels expanded the knowledge base and strengthen the partnership, the academics openly shared control of the curriculum design and facilitation.

\section{Control of curriculum design and facilitation}

When developing a learning partnership with the NGO the academics in this case found they were challenged with harmonizing the accredited study units and the needs of the organisation. Typically, the NGO needed to change in a clearly defined and strategic direction and expected learning to be productive. To serve this purpose, learning had to be a product (acquisition of discrete items of knowledge or skills, Hager 2004, 3) and process. While the worker-learners and the NGO were clear about the product (what they expected to achieve as a result of learning), they paid less 
attention to the process in both Hager (2004) and Biggs' (2007) models. Hager (2004) advocates four dimensions of productive learning that is of particular interest in the workplace. In his view productive learning redefines existing patterns and rules and involves the creation of new learning that simultaneously reshapes the environment in which the learning occurs. This reshaped environment includes the learner via 'autopoiesis', the organisation and the work practices. So the process and product of learning are inextricable linked; involves the social, cultural, and political construction of individual identities; and centres on holistic, whole-person, embodied judgements' (Hager 2004, 15). A setting for this necessitated understanding the internal dynamics of the organisational culture. Stakeholder involvement was also significant to comprehend how some of the learning outcomes would translate into functional outputs evident in the NGO's services. For instance, the involvement of the NGO’s Governing Board was seen as legitimate.

The fact that the learning objectives of the learner conformed with the board's objectives too I think made it [the curriculum] very powerful and very potent. Therefore, there was this recognition that what they [worker-learners in the courses] were doing was going to be valued. (Interviewee 03).

The development of the curriculum took into consideration not only the staff in the NGO, but indirectly their extended networks. Seeing the significance of the curriculum to the NGO's stakeholders and networks, made it imperative for the academics to ease control over the content, and work in new ways to maintain the university standards. Only through collaborative self-interest, transparency and negotiation (Smith et al. 2000) were the academics able to agree on a curriculum and delivery arrangements that suited both partners.

\section{Releasing control over content}

Universities go through a long process of accreditation of subject units. Of necessity, these units are based on explicit knowledge, so that the content of the proposed units 
can be understood by everyone in the approval chain. Accordingly, universities have become wedded to an obligation to transmit this identified explicit knowledge in full. However, this is changing in the face of demands for real world learning experiences and WIL is driving this radical change from current teaching and learning strategies. While the content of the university approved units did bear some resemblance to the desired strategic direction of the NGO, there was invariably a demand for further changes and flexibility. This is explained by the Executive Director of the

NGO

\begin{abstract}
... if I'd wanted to go and buy a product and send my staff off to a university just because I'd seen a product on the shelf and done that. It certainly would've been much easier, but fundamentally, I don't think it was what we wanted. What we were looking for was a way that we could take the university QUT on as a partner of this organisation, fundamentally in developing our business and the role that QUT played in that was actually supporting the development of our staff. So for me, it was actually about saying we need to use a whole range of tools and devices and strategies and mechanisms to actually develop people, to do the work that we do, and we need to link with a whole range of partners and collaborators around that sort of activity. So this was not different to that, so in my mind, it's the way that we operate and if QUT hadn't been able to do that, we would've gone and found it somewhere else, because that's the way we wanted it happen, yeah.
\end{abstract}

These statements clearly explain the expectations of the NGO and substantiate the need to engage its stakeholders and networks. Furthermore, the engagement of the study participants in the curriculum design, delivery and completion was an empowering experience, as explained by one participant.

I would have to say the big thing at an organisational level is probably the connectedness among colleagues, and the sense that you have been empowered from the process, that you can actually step forward and have the ability to critically analyse certain things and always question work processes. (Interviewee 06).

Certainly, controlling and protecting standards remained a core responsibility for academics, but flexibility in content and process was essential to meet the needs of the individual learners and the NGO. This relinquishing was a challenging departure from traditional mainstream teaching practices and required re-distribution of power relations between the university and the NGO. On the other hand, the academics had 
more say when it came to pedagogical decisions. For instance, they identified several pedagogical opportunities in the workplace to facilitate learning such as daily work practices; coaching; other workers (e.g., co-workers, supervisors, guides, technical experts); questioning; observing and listening to others; modelling; and workplace document procedures (Billett 2002). Of these, modelling, coaching, and questioning form the main sources of guided learning strategies. The managers and supervisors were alluded to the significance of these elements and the importance of making these and other affordances (Billett 2001) - physical spaces, resources and the time needed by the learners. The learners were briefed on their responsibilities and agency to optimise learning. This was important because it became evident that at least three learners were not prepared for an adult learning approach and wanted the academics to make all the decisions for their learning. One interviewee explained this as follows:

\footnotetext{
It was also because I had a few young people as well and we'd only been out of uni two years [after completing their undergraduate degrees] so we were used to everyone saying this is what you do, no question, whatever and that was who I was in the group with...We just wanted to get on with the work, rather than talk about how it was going to be assessed... sometime I would just have preferred to be told things and just do it. (Interviewees 3 ).
}

To accommodate their learning roles and responsibilities, some flexibility was crucial.

\section{Flexibility}

There were two main aspects of flexibility that the academics were mindful of. First, flexibility and collaboration in the composition of the content and second, its teaching, learning and assessment had to be 'located and bounded' as suggested by Boud and Solomon (2001). The unit objectives formed the basis for an educational framework to maintain the course 'standards'. This informed the educational parameters within which the learning and assessment were organized and assessed. The learning objectives of the subject units, therefore, became the 'guiding light' for 
the design of the units and also the key to ensuring that academic standards were maintained.

Senior managers and the learning cohort from the NGO were invited to contribute to the curriculum content and design - an activity highly recommended by Woollard, Zhang and Jones (2007). Two learners expressed their involvement as follows:

Certainly being able to set the assessment and discuss the assessment was really good. Yeah, it made it applied and you know, very work focused which was good. (Interviewee 08)

... that we had some responsibility and therefore power in the process appealed to me. (Interviewee 06)

The managers and learners suggested several published articles for the prescribed reading list, and negotiated specific assessment tasks to achieve the academic and organisational objectives. Only those articles that met the quality requirements for a postgraduate course were included in the reading list, the rest were listed as resources. In selecting the articles the participants only focused on the relevance of any important messages they could relate to the context of their work. The academics on the other hand needed to ensure quality and standard for example refereed publication in reputable journals. Initially, the process was frowned upon by the learners, but once the academics explained their position and the significance of refereed articles, the learners appreciated the flexibility. In this instance, the academics dominated power over the resources and perhaps did not fully appreciate the types of knowledge valued by the worker-learners or how they value such knowledge.

The assessment tasks on the other hand were aligned to the functional roles of the participants in the course, as explained by one of the senior managers who was also a learner. 
That, in fact, when people undertook that study, there was a practical application of what they were learning immediately, not just in terms of the assessments that they might undertake, but immediately, how can they - you know, the knowledge they pick up. How can that support them to be better able to work with groups... (Interviewee 04)).

Some learners who engaged in andragogical practices for the first time were initially uncomfortable with the self-directed learning nature of the course so had less input to the curriculum and learning strategies. Once again, it was mistakenly assumed that all twelve participants were self-directed learners and that they were prepared for the course based on the principles of adult learning (see Knowles 1998). One participant related a common sentiment of those with a pedagogical (as opposed to andragogical) preference.

You know when we had to work out our own learning objectives. I struggled because I guess I'm just used to people giving it [learning content] to me and just having to work with it and not really questioning it... I remember we did the learning objectives and there was other stuff along the way and we dictated how we wanted it to go and it didn’t sit very well with me and I know a couple of others in my group as well.

Understandably, staff from the NGO found it difficult to translate their intentions and learning needs in the academic language. Here, staff from the NGO and the academics had much to learn from each other. This learning is constrained if the university maintains control over the curriculum content.

In summary, this flexible and collaborative approach to refining the course materials, monitored by continual references to the learning objectives of the unit, resulted in a customised WIL curriculum that met the needs of the individuals and the NGO. The success of this co-produced curriculum is attributed to Watter's $(2005,47)$ notion of sharing: straightforwardness; honesty; shared accountability; risk taking; integrity; negotiation; and clear and jointly owned goals.

Flexibility in the timing of the key learning and assessment tasks was also important. As the provider, the university held power over the thirteen week schedule of study units each semester. This clashed with the timetable and commitments of the 
NGO. For example when the communication network in their workplace went down for nearly three weeks staff had to be re-assigned new duties to manage the crisis. Several learners were not able to complete the study tasks over that period and so the delivery dates for assessment tasks had to be re-scheduled beyond the university administration deadline. Although such administrative provisions are already in place, it is highly bureaucratic requiring approvals from several levels of authority.

Similarly, the implementation of a quality assurance system became a major business priority in the workplace and so all learning and development activities were postponed for about six months. The worker-learners withdrew for a whole semester. In another instance where a team of worker-learners were interested to stretch their project beyond one semester, the university was not able to accommodate their request. In the long term, power over the semester schedules by universities is likely to be challenged by enterprises interested in learning programs to develop workforce capacity and at the same time achieve specific organisational outcomes.

\section{Summary}

The authors initiated and developed the partnership for WIL with some unanticipated changes in power-relations. The learning cohort, their managers and the academics commenced the partnership with numerous assumptions that were discussed as they collaboratively worked at making the WIL experience beneficial to all. The partnership had a significant impact on the cultures at the NGO and the university. For instance, the transformations in negotiated responsibilities of the two partners had implications for the role of the worker-learners, academics, NGO, and for the university administrators. While the changes were generally welcomed by the NGO and the cohort of learners, it was initially uncomfortable to the university culture and its traditional position. This case study emphasizes that in the new context of WIL the 
primary product of the university is no longer the content, rather services to transform changes resulting from the learning experiences facilitated through academic studies. The move from content and a supply driven to a demand driven approach demanded a mind shift for the academics and administration.

The findings in this case study substantiate that successful WIL is premised on a learning partnership where the power over the curriculum and pedagogy are shared. It invariably involves learning by both partners (universities and organisations) and such learning is better facilitated through a re-distribution of power-relations between the two parties.

The case example in this paper highlights the fundamental importance of building a sustainable relationship, accepting changed roles of academics, focusing on a complex design and facilitation of the curriculum. Among these, relationship building and curriculum design and facilitation took the most time and effort.

In sharing their experiences the authors draw attention to some challenges and how they responded by extending boundaries and sharing the power knowledge relations. What they learned was that a partnership for WIL is a lot more complex than may seem and requires constant renegotiation of power relations in order to achieve outcomes for learners as well as their workplaces. The case study illustrates the significance of forming and sustaining a partnership within a structured, yet flexible framework that maintains the interests of all parties. As such Smith and Betts' (2000) notion of a partnership having collaborative self-interest, transparency and negotiability became central to a WIL curriculum that addresses Biggs’ (2007) 3Ps and also making learning a process as well as a product (Hager 2004). Nonetheless, the development of a partnership for WIL is a lot more complex and requires more research and debates to unpack the complexities. 
Staff from the Faculty of Education, Student Administration and Library at the Queensland University of Technology provided support during this project. The Executive Director, liaison person and members of the cohort from the NGO contributed to the evaluation data. The evaluation was funded by a small Teaching and Learning grant from the Faculty of Education.

Dr Sarojni Choy lectures in the adult education, leadership and policy subjects at the Queensland University of Technology. She has led several national research projects in e-learning, professional development, adult and community education, and employment based training. Her research interests are in adult learning, workplace learning, and workforce capacity building.

Brian Delahaye is the Associate Professor, Adult and Workplace Learning at the Queensland University of Technology. Brian's research has concentrated on adult learning, self-directed learning, developing human resource developers and the management of knowledge capital. He has published over 30 articles in national and international refereed journals and is the author of Human Resource Development: Adult Learning and Knowledge Management ( $2^{\text {nd }}$ ed.) and co-author of the How to be an Effective Trainer and Applied Business Research.

\section{References}

Biggs, J. 2007. Teaching for quality learning at university. Maidenhead: McGrawHill Education, Blacklick

Billett, S. 2001. Co-participation at work: Affordances and engagement. In Sociocultural perspectives on learning through work, ed. T. Fenwick, 66-72. San. Francisco: Jossey Bass.

Billett, S. 2002. Workplace pedagogical practices: Co-participation and learning. British Journal of Educational Studies 50, no. 4: 457-481.

Boud, D. and N. Solomon. 2001. Repositioning universities and work. In Work-based learning. A new higher education?, eds. D. Boud. and N. Solomon, 18-33. Buckingham: The Society for Research into Higher Education and Open University Press.

Boud, D. and C. Symes. 2000. Learning for real: Work-based education in universities. In Working knowledge. A new vocationalism and higher education. eds C. Symes. and J. McIntyre, 14-29. Berkshire: The Society for Research into Higher Education and Open University Press.

Choy, S. \& Delahaye, B.L. 2009a. A sustainable model for university-industry learning partnership: Issues for universities. Paper presented at the 23rd ANZAM Annual Conference, 2-5 December, Southbank, Melbourne.

Choy, S. \& Delahaye, B. 2009b. University-Industry Partnership for Pedagogy: Some Principles for Practice. Paper presented at World Association for Cooperative Education Conference, 23-26 June, Vancouver, Canada.

Choy, S. \& Delahaye, B. 2008 Leadership Development: Community of Learners in the Workplace. In Emerging perspectives on learning through work, ed. S.Billett, A. Etelapelto and C. Harteis, 149-166. London: Sense Publications.

Cresswell, J.W. (2008). Educational Research, Planning, Conducting, and Evaluating Quantitative and Qualitative Research (3 ${ }^{\text {rd }}$ ed). New Jersey, Pearson Education.

Delahaye, B. \& Choy, S. 2008. A learning partnership with a university: Some considerations for industry. Paper presented to the $22^{\text {nd }}$ ANZAM Annual Conference, 2-5 December, Auckland, New Zealand.

Delahaye, B. \& Choy, S. 2007. Using work integrated learning for management development: 
Some key elements for success. Paper presented to the $21^{\text {st }}$ ANZAM Annual Conference, 4-7 December, Sydney, Australia.

Dyer, J. and H. Singh 1998. The rational view: Cooperative strategy and sources of inter-organisational competitive advantage. Academy of Management Review 23: 660-679.

Enos, M.D., Kehrhahn, M.T. \& Bell, A. 2003. Informal learning and the transfer of learning: How managers develop proficiency. Human Resource Development Quarterly, 14, no.4: 369-387.

Foucault, M. 1980. Power/knowledge: Selected interviews and other writings, 19721977. New York: Pantheon.

Hager, P. 2004. Conceptions of learning and understanding learning at work. Studies in Continuing Education 26, no. 1: 3-17.

Hansen, M.T. 2002. Knowledge networks: Explaining effective knowledge sharing in multiunit companies. Organizational Science 13: 232-248.

Harris, R., M. Simons. and J. Moore 2005. 'A huge learning curve': TAFE practitioners' ways of working with private enterprises. Adelaide: NCVER.

Jackson, S. Farndale, E. and Kakabadse, Al. 2003. Executive development: Meeting the needs of top teams and boards. The Journal of Management Development, 22, no. 3: 185-265.

Knowles, M.S. 1998. The adult learner: A neglected species. $5^{\text {th }}$ ed. Texas: Gulf, Houston.

Knowles, M.S. 1980) The modern practice of adult education: From pedagogy to andragogy. Revised ed.Englewood Cliffs, NJ: Prentice Hall Regents.

Knowles, M.S., Holton, E.F. \& Swanson, R.A. 2005.The adult learner: The definitive classic in adult education and human resource development. Amsterdam: Elsevier.

Lave, J. and E. Wenger 1991. Situated learning and legitimate peripheral participation. Cambridge: Cambridge University Press.

Mintzberg, H. 2003. Strategies deliberate and emergent. In The economics of business strategy, ed. J.Kay, Cheltenham, UK: E.Elgar Publications.

Reagans, R. and B. McEvily 2003. Network structures and knowledge transfer: The effects of cohesion and range. Administrative Sciences Quarterly 48: 240-267.

Regans, R. and E.W. Zuckerman 2001. Networks, diversity and productivity: The social capital of corporate R\&D teams. Organizational Science 12: 502-517.

Sherwood, A.L. and J. G. Covin. 2008. Knowledge acquisition in university-industry alliances: An empirical investigation from a learning theory perspective. Journal of Product Innovation Management 25, no. 2: 162-179.

Sims, R.R. 2006. Human resource development. Greenwich, Co.: Information Age Publishing

Smith, R. and M. Betts. 2000. Learning as partners: realising the potential of workbased learning, Journal of Vocational Education and Training 52, no.4.

Solomon, N. and J. McIntyre 2000. Deschooling vocational knowledge: workbased learning and the politics of the curriculum. In Working Knowledge: The new vocationalism and higher education, eds C. Symes. and J. McIntyre, 111-122. England : SRHE and Open University Press.

Stake, R.E. 1995. The art of case study research. Thousand oaks, CA: Sage.

Tennant, M. 2000. Learning to work, working to learning: Theories of situational education. In Working knowledge: The new vocationalism and higher education, ed. C. Symes, C. and J. McIntyre, 123-143. The Society for Research into Higher Education, England. 
Torraco, R. J. 1999. Integrating learning with working: A reconception of the role of workplace learning, Human Resource Development Quarterly, 10, no. 3: 249270.

Watters, K. 2005. More than the sum: partnership for adult learning and skills. London: Learning and Skills Development Agency.

Williams, G. 2004. towards a repolitization of participatory development: Political capabilities and spaces of empowerment. In Participation: From tyranny to transformation?, ed. S. Hickey and G. Mohan, 92-106. London: Zed.

Woollard, D., M. Zhang, and O. Jones. 2007. Academic Enterprise and Regional Economic Growth: Towards an Enterprising University. Industry and Higher Education 21, no. 6: 387-403.

Wright, R. 2008. How to get the most from university relationships, MITSloan Management Review 49, no. 3: 75-80.

Zahara, S.A. and G. George. 2002. Absorptive capacity: A review, reconceptualisation, and interpersonal trust on performance. Organisation Science 9: 141-159. 